\title{
Celso Furtado: \\ uma homenagem
}

\section{GÉRARD DESTANNE DE BERNIS}

$\mathrm{O}$

QUE ESTAVA ESCRITO já em 1950 haveria de se concretizar um dia. O senhor trabalhava na CEPAL quando entrou no universo de Pierre Mendès France e, desse relacionamento, logo nasceu uma estima recíproca. A Universidade que leva o nome de Mendès France não o acolheria, então, na qualidade de um de seus grandes veteranos; posteriormente, porém, o senhor uniu-se a ela e, melhor ainda, na qualidade de um Mestre para nós todos, de um amigo! Se associo essas duas palavras é porque o senhor é dessas pessoas para quem é impossível ser um verdadeiro Mestre sem ser um grande amigo. Assim, estamos hoje reunidos. Pressinto que suas palavras serão sobre Mendès France; as minhas, entretanto, serão a seu respeito.

Faço-o, evidentemente, em nome de meus colegas que, respeitando a tradição das antigas tribos, designaram o mais velho dentre todos eles para lhe dizer que daqui a pouco sentiremos grande honra, mais ainda, imenso prazer quando lhe forem entregues as insígnias que o tornarão um de nossos colegas, no mais alto nível que uma Universidade pode conceber.

Doutor em Direito em 1944 e técnico em finanças do governo brasileiro, o senhor vem a Paris para aprofundar seus estudos de economia e é portador de uma carta. Ainda não conhece seu destinatário embora, por uma dessas artimanhas que a história aprecia, ele tenha permanecido longo tempo em seu país antes de se incorporar às Forças Francesas Livres que se preparavam para libertar a África. Foi uma temporada que ele jamais esqueceu, e, melhor ainda, lhe despertou essa paixão pela economia internacional e pelo desenvolvimento, a mesma que já era a sua, e o trouxe a Paris para estudar. O senhor entrega-lhe a carta, segue os seus cursos, descobre esse Mestre inesquecível que foi Maurice Byé, o qual também o descobre. Como fez com outros, sugere-lhe que escreva uma tese. Será L'économie coloniale brésilienne, já caracterizada pelo recurso à história para compreender a realidade presente, método que define todo o seu trabalho posterior. O senhor enxerga em Maurice Byé o que ele é, um verdadeiro professor, e tornam-se amigos. Enquanto viveu, ele lhe manifestou uma amizade que se tornaria afeição, e cada vez mais admirativa, disse-me várias vezes; era um sentimento recíproco, disse-me o senhor várias vezes.

Doutor em ciências econômicas, Cambridge o convida, e como o seu desejo é percorrer o mundo para compreendê-lo - o que fará 15 anos depois em outras circunstâncias -, o senhor para lá se dirige. Como Fellow do King's College, 
trabalha com Kaldor e Joan Robinson. Já em 1949, de volta ao seu país, Raúl Prebisch o contata de imediato, melhor dizendo, o mobiliza. O encontro ocorre na CEPAL, a mais conhecida, porque a mais ativa, sobretudo a mais inovadora das comissões econômicas das Nações Unidas, na qual o seu cargo será de diretor da Divisão de Desenvolvimento Econômico. A dupla Raúl Prebisch-Celso Furtado tem um objetivo: transformar a Terra, fazer com que ela se torne enfim capaz de alimentar e humanizar todos os seus habitantes sem qualquer discriminação, $\mathrm{e}$ permitir que eles se realizem. Isso passava por uma análise, e deixo Prebisch explicar o trabalho de ambos: "Buscávamos compreender a natureza, as causas e a dinâmica das desigualdades internacionais, estudávamos algumas de suas manifestações, as diferenças de elasticidades e a tendência à deterioração dos termos do intercâmbio para as exportações de produtos primários que a industrialização ou outras medidas políticas podiam modificar. Procurando uma explicação para esses fenômenos, assinalamos o fato de que os países latino-americanos pertenciam a um sistema de relações econômicas internacionais a que chamávamos de Centro-Periferia (...). Favorecidos por suas posições e por seu avanço tecnológico, os países industrializados organizavam um sistema global em interesse próprio. Os países que produziam e exportavam matérias-primas estavam então ligados ao Centro por seus recursos naturais. Isso condicionava a estrutura e a dinâmica de cada país (...). Da mesma maneira, o sistema de relações internacionais acentuava $o$ grau em que as riquezas da Periferia eram aspiradas (siphoned off) pelo Centro".

Tomei o texto de Prebisch para não citar todos os outros em que o senhor desenvolve essa análise, mas também porque quando a Encyclopaedia Universalis, em seu volume 18 da primeira edição de 1968 , refere-se à CEPAL, leio que "o economista brasileiro Celso Furtado foi por vários anos um dos especialistas mais destacados da Comissão à qual insuflou a um só tempo um dinamismo inegável e uma orientação de estudos duradoura."

A sua equipe, à qual devemos tantos ensinamentos, deu-nos uma lição que tentamos preservar em Grenoble: foram a história e a economia internacional que lhe permitiram compreender o presente da América Latina, sua terra natal. O senhor não raciocina em termos de dependência, e lamento que uma recente Histoire des pensées economiques haja deformado seu pensamento a esse ponto, mas, tal como Perroux, em termos de dominação, ou, para ser ainda mais preciso, de uma dupla dominação, a externa apoiando-se na interna, inicialmente reforçando-a para melhor fundar seu poder. Como Perroux, o senhor afirma que o subdesenvolvimento, produto da dominação exercida por outros, não é uma fase, mas uma situação histórica, um fenômeno estrutural.

O senhor é um teórico do desenvolvimento, porém necessita agir concretamente. Troca a CEPAL pela direção do Banco Nacional de Desenvolvimento Econômico do Brasil. Mas não se esquece de suas raízes profundas, que estão no Nordeste, longe do Rio, de São Paulo e dos negócios, uma região agrícola, dificil, pobre, com uma renda média que é um terço da renda do resto do país, sendo ali mais duro do que em outras partes o jogo dessa dupla dominação. 
A estagnação e muitas vezes a regressão não são recentes: o produto per capita diminui desde cerca de fins do primeiro século da colonização (1650), sendo acompanhado pela longa desagregação da economia açucareira na faixa litorânea e pelo isolamento do sertão, que o breve surto da produção algodoeira por ocasião da guerra de Secessão dos Estados Unidos não chega a compensar. Enquanto o Centro-Sul promove seu crescimento a partir de $1850 \mathrm{em}$ torno da expansão cafeeira, das vagas de imigração e das primeiras indústrias de transformação, a renda per capita do Nordeste continua a diminuir em cerca de $0,6 \%$ ao ano. Mais ainda, as desigualdades não cessarão de aumentar com o início da industrialização: a contribuição do Nordeste ao PNB, que era da ordem de $30 \%$ em 1939, já não passa de $11 \%$ em 1959. Mais ainda, desde o fim da guerra, por diversos meios o poder público subtraiu durante mais de dez anos uma renda estimada em US\$ 25 milhões por ano do Nordeste exportador em benefício do Centro-Sul.

Não estou inventando nada. Trata-se de uma síntese do que o senhor explicou ao meu amigo Jean Marie Martin, quando teve a gentileza de recebê-lo em Recife, em 1963. Lamentável coincidência, ele está neste exato momento em seu país, e encarregou-me de lhe transmitir seu pesar por estar ausente a este evento. Mas é isso também o que o senhor escreve em $A$ operação Nordeste, em 1959, e desenvolve, no mesmo ano, na Formação econômica do Brasil, o livro que o torna conhecido no mundo inteiro por suas seis traduções, sendo que a francesa é a antepenúltima, só em 1972 ... e em $A$ pré-revolução brasileira, publicada na França em 1964. Voltarei ao assunto.

No Banco de Desenvolvimento, o senhor insiste em cuidar prioritariamente do Nordeste. Torna-se o chefe da Superintendência para o Desenvolvimento do Nordeste, conhecida no resto do mundo por sua sigla - SUDENE - e, simultaneamente, por algum tempo, é ministro do Planejamento de Goulart, ao ser o Ministério criado por sua iniciativa. $\mathrm{O}$ ano de 1959 é histórico: Castro derruba o regime de Batista e tudo parece possível; começa-se mesmo a pensar que um mundo novo poderia nascer. Eu teria, assim como meus colegas, grande satisfação em ver Albert Hirschmann ao seu lado nesta cerimônia de homenagem e amizade respeitosa: os dois juntos iriam nos contar as conversas que tiveram quando ele foi visitá-lo na SUDENE. Ele diz algo a respeito em seus Development projects observed, de 1967. Não foi o único a se interessar por seu trabalho. Sirius, a quem por vezes chamávamos de Beuve-Méry, pede-lhe para visitar a SUDENE. De volta, redige um artigo, um desses longos artigos documentados que hoje já não se escrevem, para explicar como o senhor trabalhava, como encontrava os camponeses ajudando-os a se organizar numa verdadeira força social, para desespero da burguesia latifundiária que não lhe perdoará tal prática de mobilização social. Afirmar que ele se entusiasmou é pouco! E nós mesmos, na pequena equipe de Grenoble, às vezes com Maurice Byé quando estava presente, acompanhávamos atentamente o que a SUDENE fazia. Nessa época, iríamos constatar que a estratégia de industrialização ia sendo abandonada no México, apesar das promessas oferecidas pelas novas tecnologias siderúrgicas, provavelmente porque 
foi esquecida a mobilização da massa camponesa. Então, veja bem, o Brasil era para nós, nesta Universidade honrada por sua presença, o modelo de uma política de desenvolvimento que se apoiava na população para realizar, num só projeto, tanto a industrialização quanto a reforma agrária, os dois pilares indissociáveis, embora cada um deva ser organizado segundo sua especificidade.

Dirigir a SUDENE era, obviamente, conscientizar-que maravilhoso termo latino-americano! -; não se tratava de conceber planos abstratos, mas de trabalhar em todas as direções ao mesmo tempo, pois o desenvolvimento é global ou não existe. Os documentos da SUDENE, no mais das vezes sucintos, mas densos, precisos, voluntaristas, falam por si só: em 1961, o senhor expõe as bases da política de desenvolvimento do Nordeste, e começa pela água e pela irrigação, isto é, pela agricultura, a primeira base; em 1962, menciona um Plano Diretor com suas modalidades de execução, abordando o problema da expansão e da modernização das indústrias existentes na região, a segunda base a ser valorizada, e define as importações indispensáveis de novos equipamentos; em 1963, um documento conciso ( 35 páginas, se não me engano), anuncia o último Plano Diretor da SUDENE que eu conheço.

Creio que esse plano é bem mais do que o último de minha lista: seria o último da verdadeira SUDENE. Aqui não é o lugar para nos interrogarmos sobre as razões do golpe de Estado. Talvez não estivesse totalmente desvinculado do temor das potências dominantes externas de verem o país escapar à sua dependência, graças a uma política de desenvolvimento; talvez as forças dominantes internas tivessem medo de perder o controle de um povo que ia construindo novas estruturas socio-econômicas; talvez fosse também uma reação do grande país liberal do Norte, às voltas com dificuldades econômicas crescentes e com o declínio de sua taxa de lucro. O senhor nos dará algumas respostas amanhā, num ambiente mais adequado à análise econômica.

Professor Furtado, serei discreto sobre os acontecimentos de 1964 . O senhor suportou demasiado seus efeitos diretos e sofreu demasiado para que sejam evocados sem magoá-lo. Os militares destróem tudo, arrancam a alma da SUDENE, que era em grande parte o senhor mesmo, e a do Brasil. Pretendendo hipocritamente conservar a instituição para manter as aparências, submetem por longo tempo o seu país à dominação sem limites do grande país do Norte, que se diz liberal, aniquilam 20 anos de esforços coerentes, sujeitam o seu povo a uma junta militar que substituirá a democracia pela violência: sim, o senhor tinha razão quando na CEPAL vinculava dominação externa e dominação interna. Mas quero lhe dizer com pudor, embora claramente e com profundo respeito por sua pessoa e seus próximos, que nós todos aqui consideramos que só o honra ter sido privado de seus direitos políticos por servir a seu povo. E se esta noite vestimos as becas acadêmicas, não imagine um fútil disfarce ou um prazer de retornar a um passado esquecido, menos ainda a preocupação em imitar as grandes cerimônias teatrais e formais, e, a fortiori, uma mascarada, mas o desejo que sentimos de expressar-lhe, pelo aspecto solene conferido ao encontro, nossa emoção ao acolhermos esta noite um colega, um sábio, um homem que dedicou sua atua- 
ção ao desenvolvimento de seu povo, que foi punido por sua ação e pela lucidez de sua análise. Compreenda também que ao recebê-lo esta noite lembramo-nos com emoção de tudo o que o seu povo sofreu, de todos as marcas que conserva, de todo o atraso que acumulou em seu desenvolvimento. Mas não tenha receio, não é por estarmos assim vestidos esta noite que não iremos participar das manifestações populares quando for necessário.

Foi essa a homenagem que lhe prestaram Maurice Byé e Maurice Duverger quando o convidaram a voltar a Paris, tão logo souberam o que lhe acontecia. Este gesto muito os honra. No entanto, de início o senhor retorna por alguns meses à CEPAL, e depois será professor visitante em Yale. Recebe convites de todos os lados, mas decide que sua base será na França, em Paris, onde o encontramos uma parte do ano. $\mathrm{O}$ senhor já não se circunscreve às faculdades de ciências econômicas. Foi o seu método histórico, e não o fato de ele falar português, que o fez encontrar Braudel, seduzido por seu grande livro Formação econômica do Brasil, que será traduzido no mundo inteiro. Um se identifica facilmente com o outro: ele descobre na sua obra os modelos sucessivos que fizeram o Brasil de hoje: o açúcar, o ouro, o café; as fases da formação do Brasil estão ligadas às suas transforma-

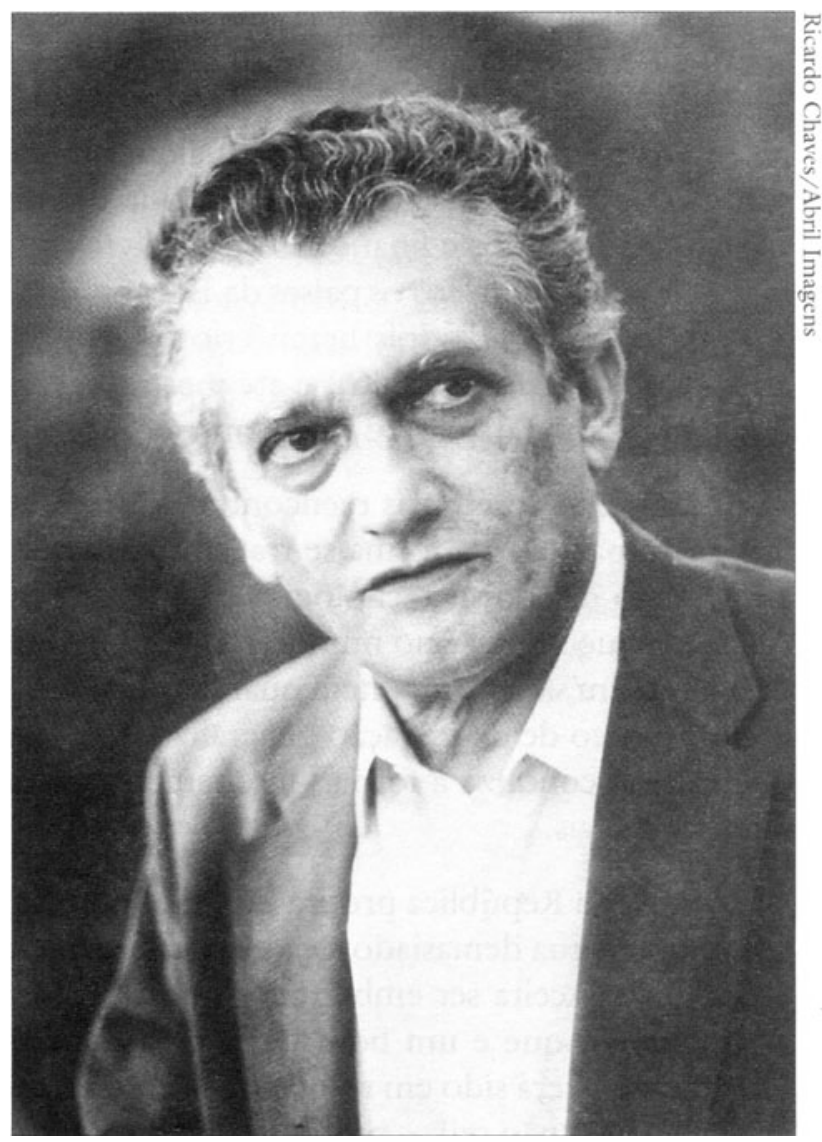

Celso Furtado: planos para o desenvolvimento do Nordeste ções estruturais, dando origem à sua industrialização. Um e outro são historiadores com uma clara consciência do peso das estruturas.

Deve-se ver nisso a revanche da história, que não se limita às artimanhas? Homem de pesquisa na CEPAL, homem de ação eficaz e batalhador, êi-lo, o economista itinerante do desenvolvimento, o professor mundialmente conhecido, reconhecido, escutado, que fala e escreve com todo o peso de sua experiência. Não lhe dão um momento de descanso. O senhor é demasiado conhecido em toda parte, é notória a sua capacidade de se interessar por tudo o que toca o desenvolvimento dos povos e todos os aspectos de suas vidas. As revistas dedicadas 
ao desenvolvimento querem-no em seus Conselhos, as instituições internacionais pedem a sua ajuda - a Universidade das Nações Unidas, o Committee for Development Planning, a South Commission e, mais recentemente, a Comissão Mundial de Cultura e Desenvolvimento, sem esquecer, num campo que lhe é novo, a Comissão Internacional de Bioética da UNESCO, na qual o senhor encontra colegas das ciências sociais e econômicas, mas também juristas - afinal, trata-se de um doutor em Direito - e biólogos com quem desenvolve um diálogo pluridisciplinar. Agora, o seu interesse volta-se para a biologia genética.

E mesmo assumindo essas missões, o construtor que o senhor será sempre continua a escrever sobre o Brasil e o desenvolvimento, sobre a dialética do pensamento e da ação, sobre os espaços de desenvolvimento, mas também, mais recentemente, por estar atento a qualquer mudança que adquire importância, sobre o desemprego, a exclusão, e ainda a crise da economia mundial e seus aspectos monetários e financeiros. Seus livros sempre foram traduzidos em inúmeras línguas, em todos os países da Europa, do Oeste e do Leste, do Norte e do Sul, assim como nos dois hemisférios o senhor é conhecido, sem esquecer, é claro, Cuba, Japão ou China, e até mesmo a Pérsia, com essa tradução em farsi que, permita-me dizer, lhe valeu em troca uma caixa de pistaches...

Em 1985 o seu país reencontra as estruturas democráticas, mas era quase um outro país, de tal forma se transformara nesses 21 anos, em especial devido ao impacto das novas tecnologias e da forte penetração do capital estrangeiro. Aliás, é o que se passa no mundo todo, conseqüência da crise que se prolonga e dela ninguém sabe como, nem quando, nem sequer se sairemos, não se podendo excluir o risco de degradação generalizada da qual vemos tantos sinais, a menos que ela nos conduza a formas inteiramente novas de atividade econômica e de relações sociais.

A Nova República precisa do senhor, mas a transição se faz sob controle, e o senhor se situa demasiado à esquerda para que lhe seja entregue um ministério econômico. Aceita ser embaixador junto à Comunidade Econômica Européia, considerando que é um bom lugar para estudar melhor a economia mundial. Finalmente - terá sido em resposta ao seu Cultura e desenvolvimento em época de crise, de 1984, não sei! - propõem-lhe ser ministro de Estado da Cultura: o país teria trocado o objetivo de seu desenvolvimento pelo de sua cultura? É um cargo que lhe traz inegável satisfação, é uma oportunidade de reencontrar o povo do Brasil por um certo aspecto de sua vida. O senhor organiza em Paris a Exposição de Arte Popular Brasileira e, mais ainda, preocupa-se em salvar a cultura do país, descobrindo também a atração que ela exerce sobre os brasileiros. Que belo coroamento para uma vida a serviço de seu povo!

Ministro do Planejamento, ministro da Cultura, talvez não seja nem seu país nem o senhor que mudou, mas o Brasil entendeu o estado de suas reflexões sobre o desenvolvimento e a cultura antes mesmo que nos fossem reveladas naquela belíssima VI Conferência François Perroux que o senhor proferiu no College de France a 15 de junho de 1994. São, pois, as suas palavras que concluirão este 
ato com o qual meus colegas me encarregaram de recebê-lo na sua Universidade Pierre Mendès France: "O estudo do desenvolvimento tem como tema central a invenção cultural, em particular a morfogênese social, embora até o momento essa temática permaneça praticamente inexplorada. Por que uma sociedade apresenta em determinado período de sua história uma grande capacidade criativa? Eis algo que nos escapa. Menos ainda sabemos por que a criatividade orienta-se numa direção precisa (...). A rigor, só se pode falar de desenvolvimento quando o homem dedica seu potencial criativo à descoberta de si mesmo, enriquecendo seu universo de valores. $O$ desenvolvimento só é real quando a acumulação material leva à criação de valores adotados por importantes segmentos da coletividade (...). Ao colocar no primeiro plano a visão sistêmica das decisões econômicas, cuja ordenação insuficiente seria a causa primária do subemprego dos fatores, lorde Keynes restabelecera a primazia do político sobre o econômico."

Meu pronunciamento foi longo demais, ainda que tenha sido abominavelmente breve, perdoem-me uma e outra inconveniência. Uma palavra a mais. Além de tudo o que eu disse, ocorre que diversas universidades o fizeram Doutor Honoris Causa. Mas permita-me dizer que nós, de Grenoble, nos felicitamos imensamente por sermos a primeira a fazê-lo fora do mundo de expressão portuguesa.

Saudação proferida pelo professor de economia Gérard Destanne De Bernis em 23 de outubro de 1996, quando o professor Celso Furtado recebeu o título de Doutor Honoris Causa da Universidade Pierre Mendès France, de Grenoble, França. 